\title{
Family-related Goals of Agritainment Proprietors in China
}

\author{
Xiuhong Wang \\ Tourism Department \\ Henan Vocational College of Agriculture \\ Zhengzhou City, China \\ e-mail: wangyuming03@163.com
}

\begin{abstract}
On the basis of field-work study with agritainment proprietors in three Chinese cities,a survey result was taken . Through comparative analyses, conclusions about familyrelated goals of agritainment proprietors in three cities were acquired, that more agritainment proprietors tended to make significant decisions together with other family members ,that more time being together with family members prompted family harmony and unity, that limited job opportunities were available to family members, that few proprietors were considering passing their businesses as family heritage, that family-related goals of agritainment proprietors in three cities displayed different traits because of education level, life value, family employment and business management.
\end{abstract}

\section{Keywords-agritainment ;proprietors ; family-related goals}

\section{INTRODUCTION}

Agritainment is one special and unique form of rural tourism. Rural tourism originated in Europe in the 19th century [1]. Modern rural tourism in China dates back to 1987 when the first Peach Blossom Festival was successfully held in Chengdu of Sichuan Province[2]. The rapid development of rural tourism in China benefits from villagers' ambitions to get rich and government supports, but overseas studies show that rural tourism plays a rather limited part in improving the proprietors' family economy.

\section{RURAL TOURISM AND FAMILY-RELATED GOALS}

\section{A. Rural tourism and Agritainment}

Overseas scholars' opinions vary on the definition of rural tourism. A typical definition, however, was given by EU and OECD, which says that rural tourism refers to tourist activities occurring in the countryside, and in which rurality is further regarded as the overall core and selling point of rural tourism [3].

There is no agreement on the definition of rural tourism and Agritainment in China, either. Quite a lot of scholars tend to consider rural tourism or Agritainment to be limited to tourist activities around the farmyard, that is, a tourist form that farmers make use of the rural scenery and natural scenic spots around their own farmyard to attract tourists. Such a definition is obviously behind the practice. Nowadays, rural tourism or Agritainment proprietors include not only farmers, but also the nation, the collective, urban residents and foreign investors. Besides, places for operation are not confined to proprietors' own farmyards any longer; there has been a tendency to shift to scenic spots or peripheral areas with beautiful scenery and convenient transportation, and thereby agritainments in scenic spots and rural tourism in the periphery of the scenic spots has come into being [4].

This article favors the definition of rural tourism or agritainment in its narrow sense, that is, rural tourism or agritainment refers to tourism occurring in the countryside and taking the natural and human landscape in rural areas as tourist attractions, in which two aspects must be included, that is, the countryside background, and natural landscape or human attractions.

\section{B. Family-related Goals}

The In this paper, a modification of family-related goals of Canadian scholar Donald Gates and Jack Carlson about rural tourism in Western Australia[5]was conducted. Family-related goals refer to nine goals related to the family of agritainment proprietors, that is, share key decisions with family members, provide family members with jobs, prevent disharmony among family members, make money to support the family, elevate family position in society, train children for future boss of the business, ensure family members have a lot of time together, pass on the family business to children and share the work equally with family members.

\section{RESEARCH METHODS AND EMPIRICAL STUDY}

\section{A. Research Methods}

Literature study method, fieldwork method and related analysis methods were used together in this article. Literature study method was applied during the preparatory stage of this article, by which family-related goals of Chinese agritainment proprietors was found to be untouched, and the questionnaire was designed by modifying related questionnaire design abroad. First-hand data were obtained through fieldwork. Then comprehensive analysis and comparative analysis methods were applied to analyze the investigation results.

\section{B. Questionnaire Design and Sample Selection}

\section{1) Questionnaire design}

The first part of the questionnaire is concerned with demographical characteristics of agritainment proprietors, which include such items as sex, age, marital status, 
respective city and resident status. The second part includes above mentioned nine family-related goals .

\section{2) Sample selection}

Shanghai, Chengdu and Wuhan, whose rural tourism develop rapidly in recent years, lie in the east, middle and west part of China respectively, so they are geographically representative. Qianwei Village and Yingdong Village in Shanghai, Mount Mulan and Cihui Farms in Wuhan, and "Five Golden Flowers" in Sansheng Town, Chengdu were selected as sample spots for empirical study.

Finally, a total 140 questionnaires were completed, among which valid questionnaires reached 136, effective rate was $97.14 \%$.

\section{Analytical Index}

Proprietors' approval degree is the degree of agreement to each family related goal. Proprietors' approval percentage is the total proportion of the agritainment proprietors who agree and absolutely agree to each family related goal. The agreement degree of family related goal is divided into absolutely- agree, agree, hard- to -say, disagree, not- agreeat- all with the evaluation value of $5,4,3,2$, and 1 in turn. Each agritainment proprietor chooses only one that he or she thinks is most proper from the five choices. The mean value of all the evaluation values of the agreement degree to each family related goal is the approval degree towards this goal. The total proportion of the agritainment proprietors who agree and absolutely agree to each family related goal is the approval percentage of this goal. Suppose the number of the proprietors agreeing to the above five choices to be a1, a2, a3, a4 and a5 in turn, proprietors' approval degree towards the family related goal will be $\left(5 a_{1}+4 a_{2}+3 a_{3}+2 a_{4}+a_{5}\right)$ / $\left(\mathrm{a}_{1}+\mathrm{a}_{2}+\mathrm{a}_{3}+\mathrm{a}_{4}+\mathrm{a}_{5}\right)$, that is, $\sum_{\mathrm{i}=1}^{5}(6-i) a_{\iota} / \sum_{i=1}^{5} a_{i}$ and the approval percentage will be $[(\mathrm{a} 1+\mathrm{a} 2) /(\mathrm{a} 1+\mathrm{a} 2+\mathrm{a} 3+\mathrm{a} 4+\mathrm{a} 5)]$ $\times 100 \%$, that is, $\sum_{i=1}^{2} a_{i} / \sum_{i=1}^{5} a_{i} \times 100 \%$.

\section{COPYRIGHT FORMS AND REPRINT ORDERS}

\section{A. Overall Analysis}

The proprietors in three cities consider share key decisions with family members as the most important family goal, with approval percentage being up to $88.2 \%$, approval degree being up to 4.44 , indicating that agritainment proprietors in three cities care a lot about their business and make key decisions together with other members of their family which is likely to avoid high investment risk that may encounter.

Ensure family members have a lot of time together and prevent disharmony among family members rank the second and the third, with approval percentage being up to $72.1 \%$ and $72 \%$, approval degree being up to 3.87 and 3.85 respectively, illustrating that agritainments play a positive role in promoting family cohesion and promoting harmony in rural communities.
Two goals about employment, namely, provide family members with jobs and share the work equally with family members ,whose approval percentage being up to $60.3 \%$ and $58.8 \%$,approval degree being up to 3.50 and 3.47 respectively, rank in the sixth and the seventh place, indicating that agritainments have positive but limited effects on providing employment for family members.

The economy-related goal, make money to support the family ranks in the fourth place, with approval percentage being up to $66.1 \%$, approval degree being up to 3.73 , indicating that nearly two-thirds of proprietors regard agritainments as a way to make a living and get rid of poverty.

The social goal elevate family position in society ranks in the fifth place, with approval percentage being up to $64.7 \%$, approval degree being up to 3.68 , showing that most proprietors have the tendency to realize their social value through running agritainments.

The two inheritance-related goals, that is, train children for future boss of the business and pass on the family business to children, rank in the last two places, with approval percentage being up to $36.7 \%$ and $41.2 \%$, and approval degree being up to 3.16 and 2.94 respectively, indicating that most proprietors hardly consider the future development of agritainments, or have strong prejudice against the small family enterprises, or have higher expectations on their family members or children, and so on.

In all, rural tourism in the three cities helps to facilitate democratic decision-making within proprietors' families, plays a positive role in promoting family cohesion and rural community harmony. Rural tourism has boosted employment in the countryside, but role it plays is rather limited. Rural tourism also improve economic conditions and enhance social status of agritainment proprietors. Most agritainment proprietors do not consider passing their business to their children as heritage as a urgent necessity or training their children to be the future boss of their businesses .

\section{B. Comparative Analysis}

With the goal share key decisions with family members, the approval percentage in Shanghai, Wuhan and Chengdu reach as high as $92 \%, 89.5 \%$ and $83.3 \%$, the approval degree attains $4.76,3.84$ and 4.58 respectively. Shanghai is located in developed region of China, and agritainment proprietors there are mainly female, so democratic decisionmaking is higher than that in the other two cities. Most agritainment proprietors in Chengdu are investors from urban Chengdu city, they have higher education and make decisions on their own. The agritainment proprietors in Wuhan are mainly male with low education, important decisions concerning agritainments are often made by the hosts, the leader of the family.

With the goal Ensure family members have a lot of time together and prevent disharmony among family members, the approval percentage in Shanghai, Wuhan and Chengdu are $76 \%, 57.9 \%, 79.2 \%$ and $68 \%, 79 \%, 70.9 \%$ respectively, and the approval degree in above three cities are 4.48, 3.26, 3.71 and $4.16,3.58,3.75$ in turn. Due to excellent operation 
performance and more time together, the agritainment proprietors in Shanghai consider running business really promote family harmony. Because of poor operation performance, which is likely to ignite conflicts among family members, running business plays rather limited role in improving family union.

With two goals concerning employment, provide family members with jobs and share the work equally with family members ,the approval percentage in Shanghai, Wuhan and Chengdu are $32.4 \%, 52 \%, 68.4 \%$ and $52 \%, 78.9 \%, 54.1 \%$ respectively, the approval degree are 2.94, 4.12, 2.95 and $3.47,3.92,2.95$ in turn. Because the good employment of family members is in Shanghai, and most proprietors' spouse and family members have jobs in urban Chengdu, the proprietors in the two cities think running agritainments plays limited role in promoting the family employment . But most agritainment proprietors in Wuhan are farmers in local community who can rarely find jobs outside running agritainments, so they cherish the job opportunities.

With one goal concerning family economy make money to support the family, the approval percentage in Shanghai, Wuhan and Chengdu are 68\%, 78.9\%, 54.2\% and the approval degree are 4.08, 3.47, 3.58 respectively. The higher approval percentage in Wuhan shows their obvious economic motivation and the strong desire to get rid of poverty, while the lower approval percentage in Chengdu shows the diversity of the proprietors' goals, which means the economy-related goal is not the only goal they are pursuing. The higher approval degree in Shanghai verifies good operation performances, while the lower approval degree in Wuhan and Chengdu shows that profitability the in both cities can not make the proprietors satisfied.

With one social goal elevate family position in society, the approval percentage in Shanghai, Wuhan and Chengdu are $64 \%, 73.7 \%$ and $58.3 \%$, the approval degree are 4.16 , $3.42,3.38$ respectively. The higher approval percentage in Shanghai shows that the good operation performance has obviously enhanced the social status of the family. Most proprietors in Wuhan want to open agritainments to gain social recognition, but poor operation performances can not make their dreams come true. The proprietors in Chengdu are not from local community, so the goals they pursue consist mainly of rural way of life and career pursuit, so they lack interest in enhancing their social statuses.

The two inheritance-related goals train children for future boss of the business and pass on the family business to children, the approval percentage in Shanghai, Wuhan, Chengdu are $44 \%, 42.1 \%, 37.5 \%$ and $44 \%, 21.1 \%, 29.1 \%$ respectively, the approval degree are 3.5, 3.52, 2.79 and $3.28,2.68,2.79$ in turn. The lower approval percentage and degree in Wuhan and Chengdu and can be explained by their poor operation performances. Due to good operation performances in Shanghai, nearly half of the proprietors hold a positive attitude to the operation of agritainments by their family members or offspring.

In all, due to better employment of family members and good operation performances in Shanghai City, the proprietors there incline to agree to family democratic decision-making, the family harmony and unity, to enhance their social statuses by running agritainments, and their motivation to make money is not strong. Because of underemployment of family members and poor operation performances in Wuhan City, the agritainment proprietors there tend to think the businesses can promote family employment and social status, but most of them do not like family democratic decision-making, but on the other hand they have strong and direct economic motivations. Because of good employment of family members, the diverse life values and poor operation performances in Chengdu City, the proprietors there do not have strong desire to promote family democratic decision-making, family unity and enhance their social statuses, and their economic motivations are either not strong.

\section{CONCLUSIONS}

Agritainments in the three cities boosts democratic decision-making within proprietors' families, plays a positive role in promoting family cohesion and rural community harmony. Rural tourism has facilitated but limited employment in rural areas. Rural tourism improve economic conditions and social status of rural community. Most agritainment proprietors hardly consider passing their business to their children as heritage or training their children to be the future boss .

Due to good employment of family members and excellent operation performances in Shanghai, the proprietors have the tendency to promote family democratic decision-making, the family harmony and unity, to enhance social status by running businesses, and their economic motivation is weak. Due to unemployment of family members and poor operation performances in Wuhan, the proprietors there have the tendency to promote family employment and social status by running businesses, but they do not like facilitating family democratic decisionmaking, and their economic motivation is rather direct and strong. Due to good employment of family members, the diversity of life values and poor operation performances in Chengdu, the proprietors have weak desire to promote family democratic decision-making, family unity and social statuses ,and their economic motivations are also very weak.

In a whole, agritainments in three Chinese cities boost democracy and family solidarity ,but proprietors lack longterm plans for the future development of agritainments, that makes rural tourism development in China tinted with a slight concern in the future.

\section{ACKNOWLEDGMENT}

This research was financially supported by the Henan Government Foundation (Grant NO. 2011B260), the Fundamental Research Funds from the Science and technology Bureau of Zhengzhou City (Grant NO. 121PPTGG464) and the Research Fund from Henan Provincial Education Department (Grant NO.2012-GH117). 


\section{REFERENCES}

[1] Wenchang Sun, Modern Tourism Development. Qingdao : Qingdao Press, 2001,pp.226.

[2] Guihua Yang, Xiuhong Wang, Rural Tourism Management Manual. Beijing: China Tourism Press, 2006,pp.1-32.

[3] Oppermann. M, "Rural Tourism in Southern Germany", Annals of Tourism Research . Vol 23.1996,pp.86-102.
[4] Wen Jun, Wei Meicai, "Discussion about Rural Tourism Development Mode" ,Ecological Economy, Vol 6,June.2002, pp.125127.

[5] Donald Getz, Jack Carlsen,"Characteristics and goals of family and owner-operated businesses in the rural tourism and hospitality sectors", Tourism Management, Vol 21. 2000, pp.547-560. 